\title{
On the interpretation of the steric and mass components of sea level variability: The case of the Mediterranean basin
}

\author{
Gabriel Jordà $^{1}$ and Damià Gomis ${ }^{1}$
}

Received 2 July 2012; revised 20 November 2012; accepted 11 December 2012; published 28 February 2013.

[1] A common practice in sea level research is to analyze separately the variability of the steric and mass components of sea level. However, there are conceptual and practical issues that have sometimes been misinterpreted, leading to erroneous and contradictory conclusions on regional sea level variability. The crucial point to be noted is that the steric component does not account for volume changes but does for volume changes per mass unit (i.e., density changes). This indicates that the steric component only represents actual volume changes when the mass of the considered water body remains constant. This is for instance the case of thermal expansions/contractions due to surface heat fluxes.

Conversely, salinity changes are often linked to net mass changes and therefore not only affect the steric component but also imply a change in the mass component that must be considered when quantifying the overall sea level budget. In this paper, we clarify the interpretation of the steric and mass components by identifying the main physical processes contributing to each of them, with particular emphasis on the role of salinity. The case of the Mediterranean Sea is examined as a paradigmatic example of a semienclosed basin where sea level components must be carefully interpreted. Because of the significant salinity changes shown by most projections of the Mediterranean climate, a misinterpretation of the steric and mass components can lead to underestimations of $\sim 40 \mathrm{~cm}$ in the sea level of the Mediterranean Sea projected for the end of the 21 st century.

Citation: Jordà, G., and D. Gomis (2013), On the interpretation of the steric and mass components of sea level variability: The case of the Mediterranean basin, J. Geophys. Res. Oceans, 118, 953-963, doi:10.1002/jgrc.20060.

\section{Introduction}

[2] Obtaining relative sea level changes at a particular location is relatively easy. Tide gauge observations of consistently good quality have been obtained for several decades at many sites referenced to a benchmark on land [see for instance the Permanent Service for Mean Sea Level archive, http://www. psmsl.org; Woodworth and Player, 2003]. Moreover, since 1993, satellite altimeters have been offering worldwide coverage of sea level anomalies with a spatial resolution suitable for regional to global scales and a temporal resolution suitable for scales longer than 1 month. Explaining the observed sea level changes is, however, more difficult.

[3] A common practice in sea level research is to analyze separately the different processes that contribute to sea level variability [see for example Huang and Jin, 2002; Lowe and Gregory, 2006; Pardaens et al., 2011]. The major forcings for global mean sea level are water mass addition/removal from the oceans (mostly due to the melting/growing of continental ice), referred to as the mass component, and

\footnotetext{
${ }^{1}$ Institut Mediterrani d'Estudis Avançats (UIB-CSIC), Esporles, Spain.

Corresponding author: G. Jordà, Institut Mediterrani d'Estudis Avançats (UIB-CSIC), c./Miquel Marqués 21, ES-07190 Esporles, Spain. (gabriel. jorda@uib.es)

(C) 2013 American Geophysical Union. All Rights Reserved. 2169-9275/13/10.1002/jgrc. 20060
}

changes in the density of the water column, referred to as the steric component [Miller and Douglas, 2004; Antonov et al., 2005; Domingues et al., 2008; Ishii and Kimoto, 2009; Levitus et al., 2012]. Changes in the global steric component are mainly attributed to thermal expansion/ contraction, with the impact of salinity changes being considered to be less important [Antonov et al., 2002].

[4] At the regional scale, however, salinity can play an important role in determining steric sea level. The Mediterranean Sea is a good example of a basin where salinity changes are at least as important as temperature changes in determining the steric component [see for instance Tsimplis and Rixen, 2002; Vargas-Yáñez et al., 2010]. In addition, the mass component is more complex at the regional scale, as it depends on local freshwater fluxes (the evaporation-precipitation-river-runoff budget) and on the mass exchanges with the neighboring basins. One of the processes contributing to water displacements and hence to regional mass changes is the mechanical forcing of atmospheric pressure and wind. This effect, which is null at the global scale, is often considered as a separate component of regional sea level variability and referred to as the atmospheric or meteorological component.

[5] Beyond the uncertainties inherent in the observations and models used to estimate the different sea level components, there are conceptual and practical issues regarding the steric and mass components that have sometimes been misinterpreted, leading to erroneous and contradictory conclusions on regional sea level variability. The crucial point to be 
noted is that the steric component does not represent volume changes, as it is often quoted, but does volume changes per mass unit (or, simply, density changes). The steric component only represents actual volume changes when the mass of the considered water body remains constant. This is the case for thermal expansion/contraction due to surface heat fluxes or when a given amount of water is replaced (e.g., due to horizontal advection) by the same amount of water but with a different temperature. Conversely, salinity changes are always linked to mass exchanges (either the amount of salt or the amount of water has to change to modify the salinity) and often result in a net mass change. Thus, changes in the mean salinity of a basin not only affect the steric component but also imply a change in the mass component that must be considered when quantifying the overall sea level budget.

[6] The Mediterranean Sea, separated from the open ocean by a sill of $\sim 300 \mathrm{~m}$ at its shallowest point, is a paradigmatic case of a semienclosed basin where the different sea level components have sometimes been misinterpreted. Because of the absence of direct observations of mass changes (only available since 2002 in the Mediterranean and elsewhere), the mass component for the last decades has been indirectly inferred by subtracting the steric and atmospheric components from total sea level. Results suggest a mass increase of the order of $1.2 \mathrm{~mm} / \mathrm{yr}$ for the period 1961-2000 [Calafat et al., 2010], while the global ocean mass increase derived from continental ice melting has been estimated in the range of $0.8-1.1 \mathrm{~mm} / \mathrm{yr}$ [Domingues et al., 2008]. Although there is no evident reason to assume that the mass of the Mediterranean Sea should increase at the rate of the global continental ice mass loss (see the last paragraph of section 3.2 for more details), it is also true that the observed increase in the mean salinity of the basin will contribute to enhance the mass increase [see Gomis et al., 2012, for an overview of the current knowledge on the long-term sea level variability of the Mediterranean Sea].

[7] Beyond the uncertainty in the values obtained for the last decades, the contribution of salinity to mass changes is expected to increase in the future, because most Mediterranean Sea projections for the 21st century show a significant increase in the mean salinity of the basin [see for example Somot et al., 2006; Marcos and Tsimplis, 2008; Somot et al., 2008; Tsimplis et al., 2008]. This has led some authors to conclude that, the mean sea level rise in the Mediterranean Sea will be smaller than the global mean in the 21 st century because the steric projections show a small or even negative trend due to the salinity increase [see for example Marcos and Tsimplis, 2008; Tsimplis et al., 2008; Carillo et al., 2012]. Such statement is based on adding the contribution of ice melting to the atmospheric and steric components and then missing the contribution of the salinity increase to the mass component. The latter factor is expected to be larger than that of continental ice melting, so missing it results in a severe underestimation of total sea level rise.

[8] This paper is precisely motivated by the contradictory results reported in the literature for estimate regional sea level change and its different components. First, we will clarify the interpretation of the steric and mass components by identifying the main physical processes contributing to each of them. However, the main objective of this paper is to determine the role of salinity in the interpretation of regional sea level variability. We also intend to give some guidelines to estimate the different sea level components from observations and the output of numerical models. The case of the Mediterranean Sea will be examined as a paradigmatic example of a semienclosed basin where sea level components must be carefully interpreted.

[9] In section 2, we formulate the separation of total sea level into its steric and mass components and clearly delimitate the meaning of each component. In section 3 , we examine academic examples to illustrate the contribution of different physical processes to each sea level component. The computation of the sea level components either from observations or from the output of numerical models is analyzed in section 4 and applied to the Mediterranean Sea in section 5. All results are summarized in section 6 .

\section{Formulation of the Steric and Mass Components of Sea Level Variability}

[10] Let us consider a water column of small horizontal section $\delta A$ located over a depth $H$ and with a free surface height $\eta(t)$, with $H$ and $\eta(t)$ measured with respect to a given vertical reference at which we set $z=0$. The mass of the water column $\delta m(t)$ is then given by

$$
\delta m(t)=\delta A \int_{z=-H}^{z=\eta(t)} \rho(z, t) d z
$$

where $\rho(z, t)$ is the density distribution along the water column. Taking the time derivative of equation (1) results in

$$
\frac{\partial(\delta m)}{\partial t}=\delta A\left\{\rho(z=\eta, t) \frac{\partial \eta}{\partial t}+\int_{z=-H}^{z=\eta(t)} \frac{\partial \rho}{\partial t} d z\right\}
$$

where $\rho(z=\eta, t)$ is the surface density, hereinafter referred to as $\rho_{\mathrm{s}}(t)$. Changes in the height of the water column can then be obtained as follows:

$$
\frac{\partial \eta}{\partial t}=\underbrace{-\frac{1}{\rho_{s}} \int_{z=-H}^{z=\eta(t)} \frac{\partial \rho}{\partial t} d z}_{\text {STERIC COMPONENT }}+\underbrace{\frac{1}{\rho_{s}} \frac{\partial}{\partial t}\left(\frac{\delta m}{\delta A}\right)}_{\text {MASS COMPONENT }}
$$

[11] The first term on the right-hand side (RHS) is the steric component of the sea level change, while the second term is the mass component. Noting that the mass of the column is related to the bottom pressure $p_{\mathrm{b}}$ and atmospheric pressure $p_{\text {atm }}$ such that $p_{\mathrm{b}}=p_{\mathrm{atm}}+g(\delta m / \delta A)$, then expression (3) can be written as

$$
\frac{\partial \eta}{\partial t}=-\frac{1}{\rho_{s}} \int_{z=-H}^{z=\eta(t)} \frac{\partial \rho}{\partial t} d z+\frac{1}{\rho_{s} g} \frac{\partial p_{b}}{\partial t}-\frac{1}{\rho_{s} g} \frac{\partial p_{\mathrm{atm}}}{\partial t},
$$

where the mass component has been split into the mass displacements produced by changes in the atmospheric pressure (the atmospheric component referred above; third term on the RHS) and mass changes due to other processes (e.g., water mass addition/removal or changes in the circulation; second term on the RHS). When a whole basin is considered, equations (3) and (4) are still valid provided that 
$\eta, \rho, \rho_{\mathrm{s}}, p_{\mathrm{b}}$, and $p_{\mathrm{atm}}$ represent horizontal averages and $\delta m$ and $\delta A$ are the total mass and extension of the basin, respectively.

[12] As stated in section 1, it is important to note from equation (3) that the steric component does not account for volume variations but does for density variations (i.e., changes in the volume per mass unit). Density changes can in turn be separated into two components, one accounting for changes in $T$ and the other accounting for changes in $S$. The first component (referred to as the thermosteric component) can be computed keeping $S$ constant in the state equation when estimating density changes, while the second (the halosteric component) can be computed keeping the temperature constant. These obviously imply neglecting nonlinear terms of the state equation, but the splitting of the steric component can be considered valid at least in the first order, because the neglected terms are of the second order.

[13] Thus, a temperature increase/decrease leads to a decrease/increase in the density and hence to a positive/negative steric change. The important point to note is that a thermosteric change results in an actual expansion or contraction of the water without any mass change. A salinity change will also lead to a change in the density and hence in the steric component. However, a salinity change also involves mass exchanges. A salinity increase, for instance, can be due to either evaporation (i.e., a decrease in the amount of freshwater keeping the salt content constant) or horizontal advection of saltier water. It is true that in the latter case the mass of the water column can remain constant if the increase in the salt content is compensated by a decrease in the water content; dynamically, this implies keeping the pressure below a certain level constant, which is the basic assumption of geostrophic balance. It is also true, however, that this does not always happen, particularly in the presence of topographic barriers. That is, salinity changes often involve changes in the mass of the water column that must be added to the steric change to obtain the actual sea level change.

[14] Equations (3) and (4) provide an overall definition for the steric and mass components of sea level variability. The physical processes that determine the two components can be inferred from further formulation. Let us consider the following mass conservation equation:

$$
\frac{\partial \rho}{\partial t}+\nabla \cdot(\rho \vec{v})=0
$$

[15] Decomposing the divergence operator into the horizontal and vertical directions and integrating along the water column, it results in

$$
\int_{-H}^{\eta} \frac{\partial \rho}{\partial t} d z+\int_{-H}^{\eta} \nabla_{h} \cdot\left(\rho \overrightarrow{v_{h}}\right) d z+\int_{-H}^{\eta} \frac{\partial}{\partial z}(\rho w) d z=, 0
$$

where $\overrightarrow{v_{h}}$ and $w$ are the horizontal and vertical components of the velocity, respectively. The last integral in this equation is simply $\left[\rho_{\mathrm{s}} w_{\mathrm{s}}-\rho_{\mathrm{b}} w_{\mathrm{b}}\right]$, where the surface $\left(w_{\mathrm{s}}\right)$ and bottom $\left(w_{\mathrm{b}}\right)$ vertical velocities are given by

$$
w_{s}=\frac{\partial \eta}{\partial t}+\vec{v}_{\mathrm{hs}} \cdot \nabla_{h} \eta+(E-P) \frac{\rho_{f}}{\rho_{s}} \quad w_{b}=\vec{v}_{\mathrm{hb}} \cdot \nabla_{h} H,
$$

where "f" and "s" stand for freshwater and surface water, respectively. $(E-P)$ represents the surface freshwater flux expressed as height changes (e.g., in millimiters per day), where $E$ stands for evaporation and $P$ for precipitation, but other freshwater sources, such as river outflow or continental ice melting, could also be included in the term. Merging equations (6) and (7) and rearranging terms, we obtain

$$
\begin{aligned}
\frac{\partial \eta}{\partial t}= & -\frac{1}{\rho_{s}} \int_{-H}^{\eta} \frac{\partial \rho}{\partial t} d z-\frac{1}{\rho_{s}} \int_{-H}^{\eta} \nabla_{h} \cdot\left(\rho \vec{v}_{h}\right) d z-\vec{v}_{h s} \cdot \nabla_{h} \eta \\
& +\frac{\rho_{b}}{\rho_{s}} \vec{v}_{h b} \cdot \nabla_{h} H-(E-P) \frac{\rho_{f}}{\rho_{s}}
\end{aligned}
$$

[16] Finally, making $\rho_{\mathrm{b}} / \rho_{\mathrm{s}} \approx \rho / \rho_{\mathrm{s}} \approx 1$, where these magnitudes are not affected by horizontal derivatives, and decomposing the second term on the RHS of equation (8) into a term accounting for the horizontal divergence of the flow and a term accounting for the horizontal advection of density, we obtain

$$
\begin{aligned}
\frac{\partial \eta}{\partial t}= & -\frac{1}{\rho_{s}} \int_{-H}^{\eta} \frac{\partial \rho}{\partial t} d z \\
& -\int_{-H}^{\eta}\left(\nabla_{h} \cdot \vec{v}_{h}\right) d z-\vec{v}_{\mathrm{hs}} \cdot \nabla_{h} \eta+\vec{v}_{\mathrm{hb}} \cdot \nabla_{h} H \\
& -\frac{1}{\rho_{s}} \int_{-H}^{\eta}\left(\vec{v}_{h} \cdot \nabla_{h} \rho\right) d z-(E-P) \frac{\rho_{f}}{\rho_{s}}
\end{aligned}
$$

[17] Alternatively, joining the second, third, and fourth terms on the RSH of equation (9), it turns into

$$
\begin{aligned}
\frac{\partial \eta}{\partial t} & =-\frac{1}{\rho_{s}} \int_{-H}^{\eta} \frac{\partial \rho}{\partial t} d z-\nabla_{h} \cdot \int_{-H}^{\eta} \overrightarrow{v_{h}} d z \\
& -\frac{1}{\rho_{s}} \int_{-H}^{\eta}\left(\vec{v}_{h} \cdot \nabla_{h} \rho\right) d z-(E-P) \frac{\rho_{f}}{\rho_{s}}
\end{aligned}
$$

[18] The first term on the RHS is the steric component as defined in equation (3), and the other terms give the different sources of mass variation: convergence/divergence of the mean horizontal velocity (second term on the RHS), horizontal density advection (third term), and surface freshwater budget (the fourth term on the RHS). Their physical meaning is rather clear except perhaps for the horizontal density advection, which appears as part of the mass component because replacing a given volume with denser/lighter water results in an increase/decrease in the mass of the water column.

[19] It is worth noting at this point that in the sea level equation there are no terms other than the steric and mass components defined in equation (3) or (10). Some studies refer to a "dynamic component" or a "circulation component" [see for example Kawabe, 1994; Pugh and Maul, 1999], but such a definition may add confusion to the balance. The effect of baroclinic circulation on sea level is 
implicitly accounted for by the steric component, as baroclinic changes are linked to changes in density. The effect of convergence/divergence of the barotropic velocity (e.g., induced by the atmospheric pressure and wind) is explicitly accounted for by one of the terms of the mass component.

[20] A second point worth clarifying is the difference between the steric term and the dynamic height used in geostrophic computations. The vertical integral of the steric term as defined in equation (3) or (10) runs along the whole vertical column whatever the value of $H$ is at each location. Conversely, the vertical integration that defines dynamic height extends down to a fixed isobar that is assumed to be at constant depth (the reference or "no motion" level). Assuming the existence of such a level isobar is equivalent to assuming that the pressure made by the water column above that level is constant, which in turn implies that the mass of the water column above that level does not change. The differences between the steric component and dynamic height will be revisited later on when some academic case studies are presented.

[21] The introduction of the thermosteric and halosteric components implies neglecting pressure effects on the density and assuming a simple linear approach for the (temporal and spatial) changes in density with $T$ and $S$ as follows:

$$
-\frac{\Delta \rho}{\rho}=\alpha \Delta T-\beta \Delta S,
$$

where $\alpha$ and $\beta$ are heat expansion and salt contraction coefficients, respectively. Under these assumptions, equation (8) results in

$$
\begin{aligned}
\frac{\partial \eta}{\partial t}= & \int_{-H}^{\eta} \alpha \frac{\partial T}{\partial t} d z-\int_{-H}^{\eta} \beta \frac{\partial S}{\partial t} d z \\
& -\nabla_{h} \cdot \int_{-H}^{\eta} \overrightarrow{v_{h}} d z+\int_{-H}^{\eta} \alpha\left(\rightarrow v_{h} \cdot \nabla_{h} T\right) d z \\
& -\int_{-H}^{\eta} \beta\left(\vec{v}_{h} \cdot \nabla_{h} S\right) d z-(E-P) \frac{\rho_{f}}{\rho_{s}}
\end{aligned}
$$

[22] The first two terms on the RHS are the thermosteric and halosteric components of the sea level, while the other terms are part of the mass component. In the next section, we examine a few academic case studies that illustrate the impact of different physical processes on each of the sea level components.

\section{Physical Processes Contributing to Sea Level Variability}

\subsection{Surface Heat Fluxes}

[23] Neglecting for the moment any horizontal gradient in the fields, it is obvious that a positive/negative surface heat flux will result in a positive/negative steric component (the first term on the RHS of equation (10)) and in a zero mass component (the other terms on the RHS). Thus, the steric component $\Delta \eta_{\text {st }}$ will reflect actual expansions/contractions of the water column that in a homogenous basin (i.e., with no horizontal gradients resulting in mass displacements) with closed boundaries (no lateral mass fluxes) will result in actual sea level rise/lowering ( $\Delta \eta_{\text {net }}$; see Figure $\left.1 \mathrm{~b}\right)$.
[24] In the open ocean, a local surface heat flux will in principle have the same effect, but in such a case the resulting horizontal pressure differences will result in interactions with the surrounding regions. A local heating of the upper layers, for instance, will cause thermal expansion, sea level rise, and, consequently, a local increase in the pressure measured at any level of the layers (and no pressure change below it). Because the changes affect the baroclinic part of the pressure field, the pressure anomaly cannot spread over long distances: the geostrophic adjustment limits the spreading to distances of the order of the baroclinic radius of deformation, which is typically of a few tens of kilometers. The ultimate result of the geostrophic adjustment will be an anticyclonic circulation surrounding a domain where the change pattern of the steric component is exactly equal to the actual sea surface height pattern. By doing such statement, we are implicitly assuming that below a certain level (e.g., the reference level for geostrophic computations), the pressure remains constant during the whole process. In practice, this is very approximately the case in the open ocean except when topographic barriers prevent the adjustment process.

\subsection{Surface Freshwater Fluxes}

[25] Considering again a homogeneous, enclosed domain, evaporation and precipitation will obviously affect the last mass term on the RHS of equation (10). The steric component will also undergo some changes due to the induced changes in surface salinity, the latent heat associated with evaporation, and the eventual heat changes produced by precipitation. However, it can be easily demonstrated that these changes in the steric component are much smaller than the changes in the mass component derived from the loss/ gain of freshwater. Considering for instance that the salt content of an evaporated layer of vertical extension $E$ spreads uniformly over an upper layer of vertical extension $U$ (see Figure 1c), the increase in the salinity of the latter layer will be $\Delta S \sim S_{\mathrm{o}} E / U$ (with $S_{\mathrm{o}}$ being the original salinity). Following equation (12), the change in the halosteric component $\eta_{\mathrm{hs}}$ will then be $\Delta \eta_{\mathrm{hs}}=-\beta U \Delta S \sim-\beta E S_{\mathrm{o}}=\beta S_{\mathrm{o}} \Delta \eta_{\mathrm{m}}$, where we have made the evaporated layer $E$ equal to the (negative) change in the mass component $\Delta \eta_{\mathrm{m}}$. Using a value of $\beta$ corresponding to $T=15^{\circ} \mathrm{C}$ and taking $S_{\mathrm{o}}=35$, for instance, we obtain $\Delta \eta_{\mathrm{hs}} \sim 0.03 \Delta \eta_{\mathrm{m}}$; that is, $30 \mathrm{~mm}$ of evaporation would result in a steric component change of about $1 \mathrm{~mm}$. Thus, in a homogeneous, enclosed basin, the impact of freshwater fluxes on sea level will essentially be that accounted for by the mass component of the sea level.

[26] In the open ocean, local sea level anomalies derived from surface freshwater fluxes will prompt the domain to interact with the surrounding regions. Unlike in the case of surface heat fluxes, local changes in the mass component affect the barotropic part of the pressure field (the bottom pressure). These pressure gradients will result in mass displacements over distances of the order of the barotropic radius of deformation, which is typically of several thousand kilometers [see for instance Huang and Jin, 2002]. Using equation (10), this means that local evaporation/precipitation patterns (with typical length scales of 10-1000 km) affecting the last term on the RHS will be practically compensated by the second term (the water convergence/divergence), because the precipitated water will spread away or water 
(a)
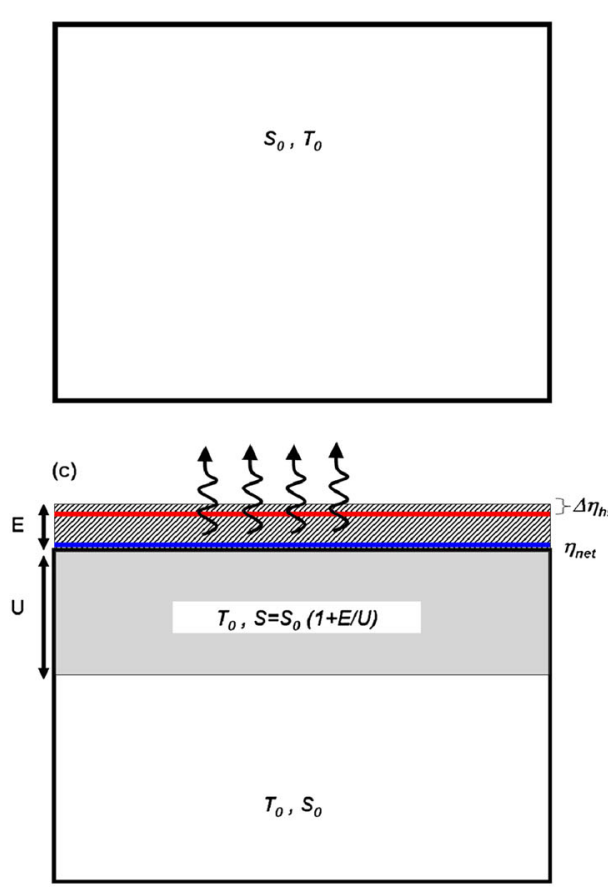

(b)

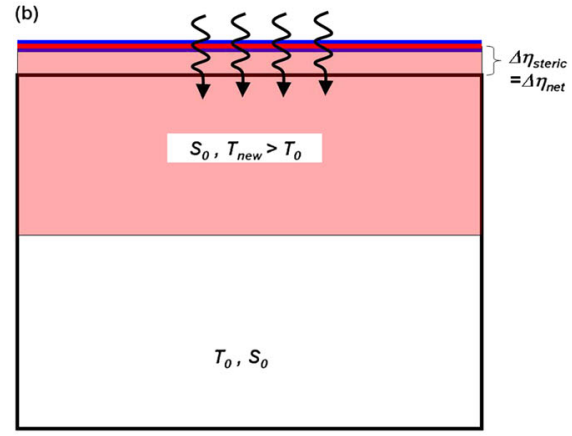

(d)

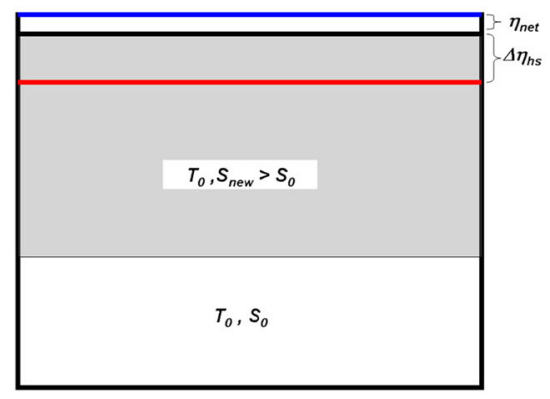

Figure 1. Sketches of an idealized case study: a closed domain with initial temperature $T_{0}$ and salinity $S_{0}$. The red line indicates the sea level change accounted for by the steric component $\left(\Delta \eta_{\text {steric }}\right)$, while the blue line indicates the actual sea level change $\left(\Delta \eta_{\text {net }}\right)$. (a) Initial situation. (b) Net positive heat flux inducing thermal expansion. (c) Net evaporation and salt redistribution. (d) Lateral advection of salt. See the text for details. Note that the vertical scales are exaggerated.

from the surroundings will come in to replace evaporation losses. Thus, the contribution of the mass component derived from local freshwater fluxes will be hardly detected over a regional domain.

[27] The melting of continental ice deserves some specific comments. The global ocean can obviously be considered as an enclosed basin, and therefore the net mass addition derived from the melting will result in a global mean sea level rise. As the dimensions of the global ocean are larger than the barotropic radius of deformation, the local pouring of freshwater can result in large-scale sea level patterns, rather than in a globally uniform sea level rise [see for example Katsman et al., 2008; Lorbacher et al., 2012]. In addition, the local response of the solid Earth to the loss of ice or the changes in the geoid due to the increase in oceanic water will create spatial patterns of sea level [Mitrovica et al., 2001]. Moreover, the local input of freshwater and cold water will also modify the baroclinic structure of the ocean and hence the geostrophic circulation [Okumura et al., 2009; Stammer, 2008].

\subsection{Lateral Salinity Advection}

[28] Let us now consider a domain where a homogeneous upper layer is substituted by another with the same volume of freshwater but with a different salt content (e.g., due to horizontal salinity advection; see Figure 1d). In this case, of the four terms on the RHS of equation (10), only the first (the steric component) and third (mass changes due to density advection) are to be considered. An increase/decrease in $S$ will result in a negative/positive steric change. An increase of 0.01 in the salinity of the first $300 \mathrm{~m}$ of the water column, for instance, will result in a steric change $\Delta \eta_{\mathrm{hs}}$ of about $-2.4 \mathrm{~mm}$ (taking $T=15^{\circ} \mathrm{C}$ ). On the other hand, the amount of salt of the column will have increased by $3 \mathrm{~kg} / \mathrm{m}^{2}$, which results in a change in the mass component $\Delta \eta_{\mathrm{m}}$ of $+3.0 \mathrm{~mm}$. [The way to translate a change in the mass component $(\mathrm{kg})$ to a change in sea level height $(\mathrm{m})$ is given by the second term on the RHS of equation (3): $\Delta \eta_{\mathrm{m}}=\Delta M / A \rho_{\mathrm{s}}$. The density used here $\left(\rho_{\mathrm{s}}\right)$ is the surface water density, not the salt density. The physical explanation relies on the fact that we are not actually computing the volume occupied by the salt (which is very small, as in any dissolution). What equation (3) is saying is that the steric component gives volume changes per mass unit (density changes) so that we need to consider the mass changes in the water column, independently of whether they are due to salt or water changes, to obtain actual volume changes (i.e., sea level changes).] In summary, the net result of the salinity increase is thus a net sea level increase $\eta_{\text {net }}$ of about $+0.6 \mathrm{~mm}$ and not a sea level decrease, as it would be concluded looking only at the steric component. This rather trivial result from the physical point of view has often been ignored or misinterpreted, as in the literature we can find quite a few papers stating that the water column "contracts" in response to a salinity increase.

[29] The key issues to realize are, first, that salinity changes affect the mass component and not only the steric component and, second, that the mass component of the sea level variability as defined in equation (3) or (10) accounts for any change 
in the mass of the water column (e.g., salt changes) and not only for changes derived from freshwater addition or subtraction.

[30] In the open ocean, the local bottom pressure (mass) increase derived in principle from horizontal salinity advection (the third term on the RSH of equation (10)) will be usually compensated by the horizontal advection of sea surface height (the third term on the RSH of equation (9), included within the second term on the RSH of equation (10)) and then result in a small mass component. Under the geostrophic assumption, the compensation will be complete and the contribution of the mass terms will be null; that is, the steric component will reflect the actual sea level lowering. However, topographic barriers and any other cause preventing the dynamic adjustment of the fields will allow for the mass component to also be considered along with the steric component. A semienclosed basin such as the Mediterranean Sea is one of the clear cases in which the basin mean steric component by itself will not account for actual sea level changes, because the Strait of Gibraltar sill prevents pressure adjustments between the two sides of the strait at depths greater than the sill depth and the narrowness of the strait prevents the geostrophic adjustment of the along-strait pressure differences at shallower levels. The flow through the Strait of Gibraltar is hydraulically controlled [see for instance Farmer and Armi, 1988], and the sea level gradient across it is determined by the hydraulic regime, not by a geostrophic balance. Thus, the Mediterranean basin is a clear example where the steric component and total sea level can be very different, making the determination of the mass contribution compulsory to understand the actual sea level variability.

\section{Quantification of the Different Sea Level Components}

\subsection{Quantifying the Sea Level Components From Observations}

[31] Identifying the different sea level components from observations is not an easy task. For instance, we cannot expect to quantify each of the terms in equation (10) because current measurements, when available, are not accurate enough. However, we can in principle quantify each of the terms in equation (3). The left-hand side (LHS) term can be estimated from altimetry data, where it is important to note that altimetry is usually corrected for the atmospheric contribution to sea level. The resolution of altimetry data is enough to represent monthly and longer temporal scales and from regional to global spatial scales.

[32] The steric component can be estimated from hydrographic observations, albeit with limited accuracy due to the usually uneven spatiotemporal distribution of available data [see for example Tsimplis et al., 2011]. In practice, the vertical integral in equation (3) can be limited to the upper levels if steric changes are considered to be small at low levels [see for example Calafat and Marcos, 2012]. An additional approximation is to set the upper limit of the integral to $\mathrm{z}=0$ instead of $z=\eta(t)$; for a vertical domain of $1000 \mathrm{~m}$, for instance, this results in relative errors of the order of $10^{-4}$ for the steric changes, which are absolutely negligible in front of other uncertainty sources, such as the uneven spatiotemporal distribution of observations. Obtaining the thermosteric and halosteric terms appearing in equation (10) from hydrographic data does not represent any problem beyond those mentioned for the whole steric component.

[33] The mass component of equation (3) can be obtained from gravimetry data (e.g., from the GRACE mission, available for 2002), which permit the resolution of the mass field at spatial scales of a few hundred kilometers. That is, we can estimate changes in the Mediterranean basin as a whole, for instance, but not at the sub-basin scale. In addition, gravimetry data are usually corrected for the atmospheric contribution [Fletchner, 2007] so that using altimetry on the LHS of equation (3) and gravimetry on the RSH will be consistent. Of course if total sea level is to be recovered, the atmospheric component of the sea level must be evaluated independently and added to both sides of equation (3).

[34] If we know the salinity changes $\Delta S(x, y, z)$ over a certain period, we can infer their contribution to the mass component of the sea level over a domain $A$ from equation (3) as follows:

$$
\Delta \eta_{m, \text { salt }}=\frac{\Delta m_{\text {salt }}}{\rho_{s} A} \approx \frac{1}{\rho_{s} A} \int_{A} \int_{z=-H}^{z=0} \Delta S d x d y d z \approx \frac{\bar{H}}{\rho_{s}} \Delta \bar{S},
$$

where $S$ is the mass of salt per volume unit (if $S$ is given in practical salinity units, it is practically equivalent to having it in kilograms per cubic meter), $\Delta \bar{S}$ is the change in the mean salinity, and $\bar{H}$ is the mean depth of the domain. By subtracting the result of equation (13) from total mass changes (e.g., inferred from GRACE data), we would obtain the addition/subtraction of freshwater.

\subsection{Quantifying the Sea Level Components From Numerical Models}

[35] Inferring sea level and its components from numerical model outputs merits a special comment. First of all, it must be noted that many ocean models use the Boussinesq approximation; that is, they conserve volume rather than mass [Greatbatch, 1994; Mellor and Ezer, 1995; Huang and Jin, 2002]. Therefore, these models cannot account for net expansions/contractions over the model domain (e.g., due to temperature increases/decreases). They can reproduce the sea level gradients associated with density gradients and mass exchanges within the model domain, but the sea level change averaged over the domain is always zero. A common way to overcome this limitation is computing a spatially constant, time-varying value $\Delta \eta_{\mathrm{B}}$ that accounts for the expansion/contraction integrated over the whole model domain $A$ [Greatbatch, 1994] as follows:

$$
\Delta \eta_{B}=-\frac{1}{\rho_{s} A} \int_{A} \int_{z=-H}^{z=0} \Delta \rho d z d A
$$

This constant is computed for each time step and added a posteriori to the sea surface height maps provided by the model.

[36] A quick look at equation (3) is enough to identify this constant with the steric component of the sea level, which, according to the case studies presented in section 2 , is sometimes a good approximation to total sea level changes and sometimes not. In global models, for instance, and under the assumption that the mass remains constant over the model domain (i.e., in the case that the net expansion/contraction is only due to temperature changes and not to salinity 
changes), $\Delta \eta_{\mathrm{B}}$ will provide the proper correction to the sea level fields from Boussinesq models. This is not true, however, for regional models, which allow the exchange of $T, S$ properties through the open boundaries of the domain and hence for changes in the mass content of the domain. In the case of net salinity advection, for instance, equation (14) will give negative values for $\Delta \eta_{\mathrm{B}}$, while we have seen in section 3.3 that sea level could be increasing rather than decreasing. Thus, if total sea level has to be computed from regional models, some cautions are needed. We consider here two cases: when the regional model is nested into a global model so that information about the global ocean is transferred through the open boundaries and when it is not.

[37] In the case of a nested regional model, we will assume that the numerical definition of the open boundary conditions does not induce errors (i.e., there is a "perfect" transfer of information from the global ocean to the regional model). In this case, the total sea level obtained from the global model should be prescribed at the open boundaries of the regional model. That is, the dynamic part of sea level $\Delta \eta_{\mathrm{D}}$ (the sea surface height variable from the global model that has zero average over the global ocean) plus the timevarying $\Delta \eta_{\mathrm{B}}$ is given by

$$
\Delta \eta\left|\begin{array}{l}
\mathrm{OBC} \\
\text { regional }
\end{array}=\Delta \eta_{D}\right| \begin{aligned}
& \mathrm{OBC} \\
& \text { global }
\end{aligned}+\Delta \eta_{B} \text { global }
$$

[38] By doing this, the sea surface height variable of the regional model will account for total sea level. The spatial gradients will still be defined by the regional dynamics, while the absolute value accounting for net expansion/contractions will be set at the open boundaries from the information provided by the global model. The issue to be noted here is that $\Delta \eta_{\mathrm{B}}$ must be computed from the global model outputs and not from the regional model, because the latter model does not necessarily fulfil the assumption underlying equation (14): that the mass remains constant within the model domain.

[39] A different approach must be followed when the regional model is not fully nested into a global model so that no information about sea surface elevation is provided at the boundaries [see for instance Somot et al., 2006; Artale et al., 2010; Beuvier et al., 2010]. In this case, the time-varying constant $\Delta \eta_{\mathrm{B}}$ can only be computed regionally, but expression equation (14) must be modified to include the mass component that was neglected at the global scale. Because of the volume conservation, mass changes can only come from changes in the mean salinity within the model domain; therefore, the time-varying constant to be added to the sea surface height given by the model is

$$
\Delta \eta_{B \text { reg }}=-\frac{1}{\rho_{S} A} \int_{A} \int_{z=-H}^{z=0} \Delta \rho d z d A+\frac{1}{\rho_{S} A} \int_{A} \int_{z=-H}^{z=0} \Delta S d z d A
$$

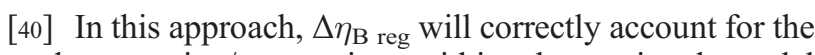
actual expansion/contraction within the regional model domain, but part of the interaction with the global ocean is missed. That is, the regional model will incorporate the global baroclinic signal if temperature and salinity boundary conditions are set from the global model, but it will not include other sea level components, such as barotropic mass displacements (i.e., induced by remote winds or ice melting) reaching the boundaries of the domain. Therefore, sea level results obtained from such regional models must be interpreted with caution.

\section{The Case of the Mediterranean Sea}

[41] The concepts introduced in the previous sections are now illustrated in the case of the Mediterranean Sea using both observations (covering the last decades of the 20th century) and model data (baroclinic model projections for the 21 st century). For the last decades, monthly fields of the total sea level of Mediterranean Sea for the period 1950-2010 have been obtained from a reconstruction that merges altimetry and tide gauge information [Calafat and Jordà, 2011]. The reconstructed sea level fields do not include the atmospheric component. The steric, thermosteric, and halosteric components are computed from the Ishii hydrographic database [Ishii and Kimoto, 2009], which consists of monthly $1^{\circ} \times 1^{\circ}$ gridded global temperature and salinity fields resulting from applying an objective analysis to historical in situ data. This data set covers the surface to $700 \mathrm{~m}$ so that the steric component has been computed down to that depth. At the global scale, the consistency between altimetry, steric sea level, and GRACE observations has been controversial, partly due to the short period of data available [Willis et al., 2008; Leuliette and Miller, 2009; Cazenave et al., 2009] and partly due to the uncertainties inherent in the computation of the steric and mass components [Chambers, 2006]. In the Mediterranean Sea, the sea level budget appears to be consistent: Fenoglio-Marc et al. [2006] and Calafat et al. [2010] showed that the subtraction of the steric component from total sea level provides an accurate estimate of the mass component from intraseasonal to interannual scales.

[42] Figure 2 shows the time evolution of the mean sea level of the Mediterranean Sea (with the atmospheric component subtracted) for the last decades. Calafat et al. [2010], who used the same data set as that described here, already pointed out that the mass component shows a higher variability than the steric component and, more apparently, a larger trend (Figure 2a). In fact, the trend of the steric component is slightly negative, so the positive trend in total sea level is entirely due to the mass component (see Table 1). Splitting the steric component into its thermosteric and halosteric contributions shows that both have negative trends, which reflect a mean temperature decrease and a mean salinity increase over the 3D domain (Figure $2 \mathrm{~b}$ and Table 1). In addition, splitting the mass component into its salt water and freshwater contributions reveals that the salt increase has a small impact on the total mass trends (see Figure 2c and Table 1). Finally, we show total sea level split into the actual physical processes that drive sea level variability (Figure 2d): thermosteric expansion/contraction, addition/subtraction of water, and haline net effect (the halosteric contribution plus the salt mass change). As explained in the case studies, the halosteric component by itself is not representative of the actual role of salinity changes; physically, a salinity increase/decrease results by itself in a net sea level increase/decrease, but there can be water displacements associated with the salinity changes through dynamic constraints (e.g., the geostrophic balance) that may result in opposite changes. 
a)

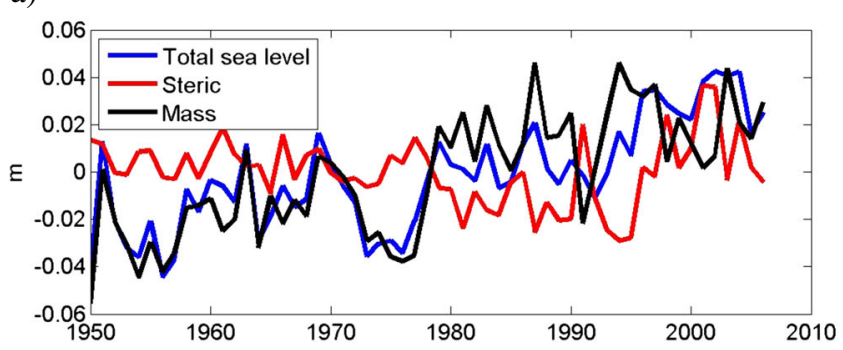

b)

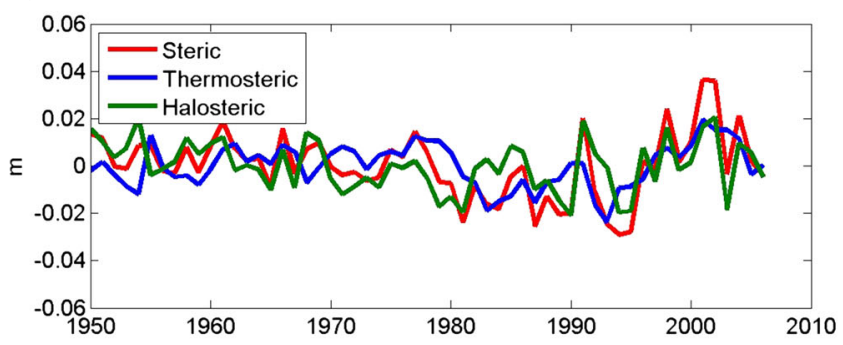

c)

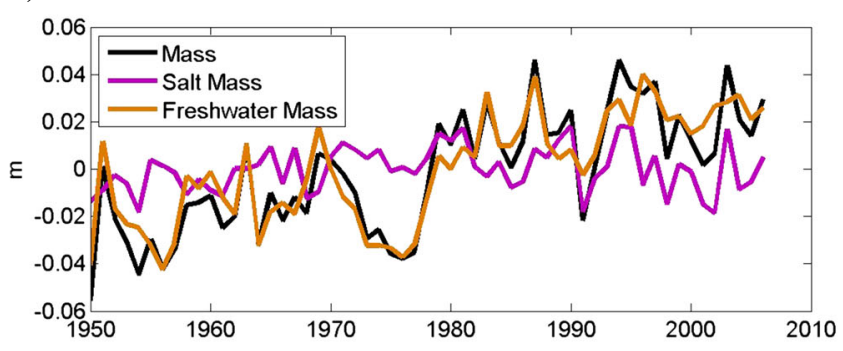

d)

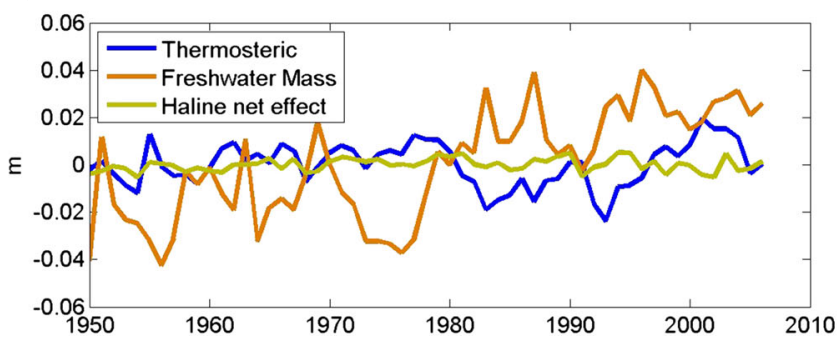

Figure 2. Time evolution of the mean sea level of the Mediterranean Sea and its components for the last decades. (a) Total sea level (reconstructed from tide gauge and altimetry data, with the atmospheric component subtracted), the steric component as computed from the Ishii hydrographic database, and the mass component inferred as the difference between total sea level and steric sea level. (b) The steric component split into its thermosteric and halosteric contributions. (c) The mass component split into its water addition and salt addition contributions. (d) The physical processes determining sea level changes: thermosteric expansion/contraction, addition/subtraction of freshwater, and haline net effect (the halosteric contribution plus the salt mass change). See the text for details.

[43] In summary, from the Ishii database we can deduce that during the last decades, the sea level trend of the Mediterranean Sea has been mostly driven by an increase in the mass content of the basin. The mass increase is mainly due to an increase in the incoming Atlantic Ocean water,
Table 1. Linear Trends of the Mean Sea Level of the Mediterranean Sea (With the Atmospheric Component Subtracted) and Its Components for the Period 1960-2000

\begin{tabular}{|c|c|c|}
\hline Time Series & Data Set & Trend (mm/yr) \\
\hline Total sea level & $\begin{array}{l}\text { Reconstruction from tide } \\
\text { gauges and altimetry data }\end{array}$ & $+0.88 \pm 0.21$ \\
\hline Steric component & Ishii database & $-0.48 \pm 0.17$ \\
\hline Mass component & $\begin{array}{l}\text { Inferred as total sea level } \\
\text { minus the steric component }\end{array}$ & $+1.27 \pm 0.25$ \\
\hline $\begin{array}{l}\text { Thermosteric } \\
\text { contribution }\end{array}$ & Ishii database & $-0.27 \pm 0.12$ \\
\hline Halosteric contribution & Ishii database & $-0.10 \pm 0.14$ \\
\hline Salt mass contribution & Ishii database & $+0.12 \pm 0.17$ \\
\hline $\begin{array}{l}\text { Freshwater mass } \\
\text { contribution }\end{array}$ & $\begin{array}{l}\text { Inferred as mass component } \\
\text { minus the salt mass }\end{array}$ & $+1.16 \pm 0.23$ \\
\hline Haline net effect & $\begin{array}{l}\text { Halosteric contribution } \\
\text { plus salt mass }\end{array}$ & $+0.03 \pm 0.04$ \\
\hline
\end{tabular}

${ }^{\text {a }}$ Some of the time series were computed from observations, while others were obtained as the addition or subtraction of other parameter time series. The uncertainties quoted for the trends only reflect the statistical uncertainties related to the variability of the time series.

with the salinity increase playing a small role. The negative temperature trend contrasts with the increase in the global mean temperature. This regional negative anomaly in the temperature has been related to the highly positive NAO phase dominating the 1960s-1990s [see Tsimplis and Rixen, 2002]. From the mid 1990s, the temperature and hence the steric component have increased significantly following the decrease in the NAO index, but the increasing period is still too short to result in overall positive trends. As pointed out in section 1, the magnitude of the steric component, its contributions, and other parameters computed from hydrographic databases are strongly handicapped by the scarcity of observations. The differences in the trends computed from different databases are rather large, although all of them agree in that the salinity of the Mediterranean Sea has been increasing during the last decades.

[44] Most projections for the 21st century confirm the salinity trends observed during the last decades. The Mediterranean basin is expected to experience higher evaporation and less precipitation than at present, which would lead to its salinification [Somot et al., 2006; Somot et al., 2008; Dubois et al., 2012]. (It is also true, however, that some projections show a salinity decrease derived from the advection of less salty Atlantic Ocean water through the Strait of Gibraltar [Gualdi et al., 2011].) All projections also show markedly positive trends in the mean temperature so that the thermosteric component shows a positive trend accounting for the thermal expansion. Among the projections that show a salinity increase and hence a halosteric component with a negative trend, the total steric change spreads from small positive to small negative values due to the high degree of cancellation between the thermosteric and halosteric contributions [see for example Marcos and Tsimplis, 2008; Carillo et al., 2012]. As stated in section 1, this has led to the unfounded conclusion that the mean sea level of the Mediterranean Sea will rise more slowly than the global mean during the 21 st century.

[45] To illustrate that the last statement derives from a misinterpretation of the steric and mass components, we use the outputs of a Mediterranean regional climate ocean 
model [Jordà et al., 2012a, 2012b]. The model uses the NEMOMED 8 code at $1 / 8 \mathrm{deg}$ of spatial resolution [Beuvier et al., 2010] forced by the outputs of the ARPEGE-v4 climate model for the period 1950-2100 under the A2 scenario. This regional model shares the same configuration with other regional models [Somot et al., 2006, 2008; Artale et al., 2010] and does not account for mass changes in the nearby Atlantic Ocean due to ice melting or water mass redistribution.

[46] Figure 3a shows the thermosteric and halosteric contributions which in that projection result in a slightly negative trend for the steric component (i.e., negative halosteric changes slightly dominate over the positive thermosteric changes; see Table 2). However, as stressed above, the halosteric component is not telling the whole history about the role played by salinity. The increase in the mass content derived from the increase in the salt content is larger than the halosteric component; that is, it will result in a sea level increase of several centimeters by the end of the $21 \mathrm{st}$ century. Together with the thermosteric contribution, this
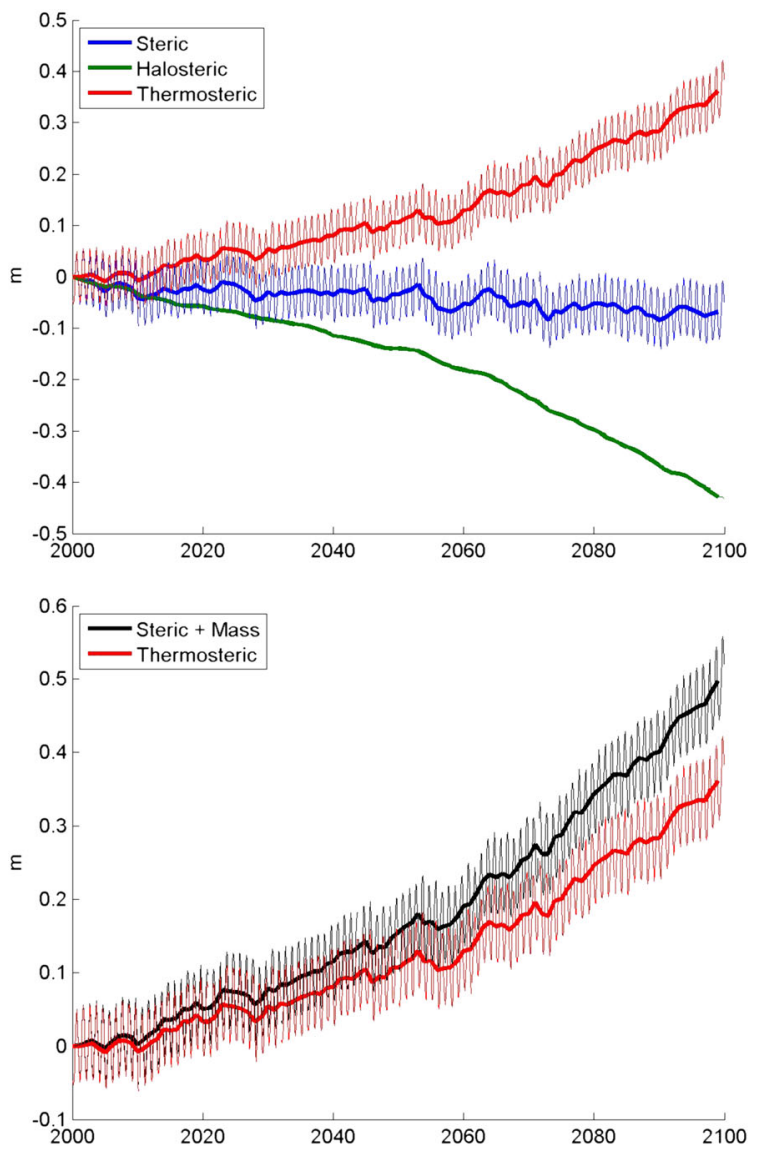

Figure 3. Time evolution of the sea level components computed from a Mediterranean regional climate model for the period 2000-2100. (Top) The steric component and its thermosteric and halosteric contributions. (Bottom) The steric component plus the salt mass contribution and the thermosteric component. Thin lines are monthly values, while thick lines are annual mean values.
Table 2. Linear Trends and Change in 100 Years Projected by a Mediterranean Regional Climate Model for the Period 2000-2100 a

\begin{tabular}{lcc}
\hline Parameter & $\begin{array}{r}\text { Linear Trend (mm/yr) for the } \\
\text { Period 2000-2100 }\end{array}$ & $\begin{array}{c}\text { Change in } \\
\text { 100 Years }(\mathrm{cm})\end{array}$ \\
\hline $\begin{array}{l}\text { Steric component } \\
\text { Thermosteric }\end{array}$ & $-0.58 \pm 0.04$ & -6.86 \\
contribution & $+3.49 \pm 0.05$ & +36.09 \\
$\begin{array}{l}\text { Halosteric } \\
\text { contribution }\end{array}$ & $-4.04 \pm 0.03$ & -42.87 \\
$\begin{array}{l}\text { Salt mass change } \\
\text { Steric plus salt mass }\end{array}$ & $+5.38 \pm 0.03$ & +56.57 \\
\hline
\end{tabular}

${ }^{\mathrm{a}}$ The uncertainties quoted for the trends only reflect the statistical uncertainties related to the variability of the time series.

results in a sea level increase of about $50 \mathrm{~cm}$ (see Figure $3 \mathrm{~b}$ and Table 2).

[47] Two crucial issues are to be noted at this point. The first one is that estimating total sea level rise in the Mediterranean Sea by adding only the contribution of continental ice melting (not included in climate models) to the steric component is wrong, because the mass increase associated with the salt increase is missed. In the case of the Mediterranean Sea and the particular simulation analyzed here, the salt contribution ( $56 \mathrm{~cm}$ in Table 2$)$ is much larger than the contribution from ice melting [currently estimated between 4 and $20 \mathrm{~cm}$ for 2100; IPCC, 2007]. Thus, missing the salt contribution will lead to projecting a sea level rise of less than $15 \mathrm{~cm}$ for 2100 on top of the $50 \mathrm{~cm}$ that the simulation used here indicates. To obtain the spatial distribution of total sea level trends within the model domain, a spatially constant (but varying in time) value has to be added to the sea surface height trends given by the model at every grid point. That constant is the result of equation (16) (the steric plus salt mass value in Table 2) and not that of equation (14) (the steric component alone).

[48] The second issue to be recalled is that we are only analyzing the steric component and the contribution of salt to the mass component. The model considered here is not fully coupled with a global model and therefore does not include such sea level components as barotropic mass displacements induced by remote winds or ice melting and reaching the boundaries of the model domain [Calafat et al., 2012]. Moreover, it does not have enough resolution to solve neither the hydraulic regime at the Strait of Gibraltar nor the along-strait sea level drop. That is, the projected values are more intended to illustrate the role of salinity in regional sea level estimates than to give accurate projections for the sea level of the 21 st century.

\section{Summary and Conclusions}

[49] The equations and case studies presented in this paper intend to demonstrate that the steric component of the sea level can be rather different from total sea level changes. In particular, the halosteric contribution does not represent by itself actual sea level variations, because changes in the salinity of the water column also imply changes in the mass component. We have shown for instance that the salt contribution to the mass component is always slightly larger than (in absolute value) and has a sign opposite that of the halosteric component. This explains why the net impact of 
adding/subtracting salt in an enclosed basin is a slight sea level increase/decrease. At open sea, however, high/low salinity advection is usually linked to low/high sea level advection, to the point that under the geostrophic balance the two advections compensate each other and the mass of the water column remains constant. In such a case, the steric component is certainly accounting for total sea level. In general, the only way to ensure the reliability of total sea level estimates is by adding the steric component to total mass changes (which include both salt water and freshwater changes).

[50] Expressing total sea level in terms of the thermosteric component plus the water mass change (i.e., neglecting the role of salt changes) can sometimes be a better approximation than adding the freshwater mass changes to the whole steric component. However, whenever possible, total sea level should be computed by either adding the steric and total mass components or, following a more physical approach, adding the thermosteric component (representing the thermal expansion), the changes in the freshwater content, and the net haline effect (the halosteric component plus the changes in the mass of salt). Conversely, subtracting the steric component from total sea level will provide the changes in the total mass, which can be different from the changes in the amount of freshwater if variations in the salt content are large.

[51] In a climate change context, the issues presented here gain in importance, particularly for semienclosed basins, such as the Mediterranean Sea. In such a case, neglecting the contribution of the salt increase to the mass component when estimating total sea level [see for example Marcos and Tsimplis, 2008; Tsimplis et al., 2008; Carillo et al., 2012] can result in a severe underestimation of actual sea level rise. This extended misinterpretation of the steric and mass components is probably due to several reasons. One may be that computations carried out at the global scale have been repeated at the regional scale without reviewing basic assumptions, such as the mass conservation within the considered domain. Even when changes in the mass of the ocean are considered, the interpretation of observations in a global context and that in a regional context may differ. Thus, changes in the mass of the global ocean computed from gravimetric observations will essentially reflect changes in the freshwater contents, because the global amount of salt is assumed to be constant. Conversely, mass changes obtained from regional gravimetric observations will include the changes in the salt content of the region and not only freshwater changes.

[52] Another reason for a misleading interpretation is the formal similarity between the steric component of the sea level and dynamic height. Under the geostrophic balance, high/low density values are really associated with low/high sea level. However, if dynamic adjustment is not possible (e.g., due to topographic barriers), high/low densities will no longer be associated with low/high sea level.

[53] Finally, special attention must be paid when inferring sea level from regional model outputs. Not taking into account the different issues presented here can also lead to very misleading conclusions. In such a sensitive issue as climate change, where the impact of the expected changes in the physical variables is very relevant, a misinterpretation of the steric and mass components inferred from models may add more confusion than light to the current knowledge.
[54] Acknowledgments. This work has been carried out in the framework of the projects VANIMEDAT-2 (CTM2009-10163-C02-01, funded by the Spanish Marine Science and Technology Program and the E-Plan of the Spanish Government) and ESCENARIOS (funded by the Agencia Estatal de METeorología). G. Jordà acknowledges a JAE-Doc contract funded by the Spanish Research Council (CSIC) and the European Science Foundation. We thank R. Aznar for kindly providing the outputs of the NEMOMED8 simulation. We also thank M. Tsimplis, F. M. Calafat, S. Somot, F. Sevault, M. Marcos, E. Álvarez-Fanjul, S. Monserrat, and A. Amores for useful discussions.

\section{References}

Antonov, J. I., S. Levitus, and T. P. Boyer (2002), Steric sea level variations during 1957-1994: Importance of salinity, J. Geophys. Res., 107(C12), 8013, doi:10.1029/2001JC000964.

Antonov, J. I., S. Levitus, and T. P. Boyer (2005), Thermosteric sea level rise, 1955-2003, Geophys. Res. Lett., 32, L12602, doi:10.1029/ 2005 GL023112.

Artale, V., et al. (2010), An atmosphere-ocean regional climate model for the Mediterranean area: assessment of a present climate simulation, Climate Dyn., 35(5), 721-740, doi:10.1007/s00382-009-0691-8.

Beuvier, J., F. Sevault, M. Herrmann, K. Kontoyiannis, W. Ludwig, M. Rixen, E. Stanev, K. Béranger, and S. Somot (2010), Modelling the Mediterranean Sea inter-annual variability during 1961-2000: Focus on the Eastern Mediterranean Transient, J. Geophys. Res., 115, C08017, doi:10.1029/2009JC005950.

Calafat, F. M., M. Marcos, and D. Gomis (2010), Mass contribution to Mediterranean Sea level variability for the period 1948-2000, Global Planet. Change, 73, 193-201, http://dx.doi.org/10.1016/j.gloplacha.2010.06.002.

Calafat, F. M., and G. Jordà (2011), A Mediterranean sea level reconstruction (1950-2008) with error budget estimates, Global Planet. Change, 79, 118-133, doi:10.1016/j.gloplacha.2011.09.003.

Calafat, F. M., and M. Marcos (2012), Comparison of satellite altimetry sea level anomalies and hydrographic observations in the Mediterranean Sea, Scientia Marina, 76(3), 429-439, doi:10.3989/scimar.03515.02G.

Calafat, F. M., G. Jordà, M. Marcos, and D. Gomis (2012), Comparison of Mediterranean sea level variability as given by three baroclinic models, J. Geophys. Res., doi:10.1029/2011JC007277.

Carillo, A., G. Sannino, V. Artale, P. M. Ruti, S. Calmanti, and A. Dell'Aquila (2012), Steric sea level rise over the Mediterranean Sea: present climate and scenario simulations, Climate Dyn., doi:10.1007/s00382$012-1369-1$, in press.

Cazenave, A., K. Dominh, S. Guinehut, E. Berthier, W. Llovel, G. Ramillien, M. Ablain, and G. Larnicol (2009), Sea level budget over 2003-2008: A reevaluation from GRACE space gravimetry, satellite altimetry and Argo, Global Planet. Change, 65, 83-88, http://dx.doi.org/10.1016/j. gloplacha.2008.10.004.

Chambers, D. P. (2006), Observing seasonal steric sea level variations with GRACE and satellite altimetry, J. Geophys. Res., 111, C03010. doi:10.1029/2005JC002914.

Domingues, C. M., J. A. Church, N. J. White, P. J. Glecker, S. E. Wijffels, P. M. Barker, and J. R. Dunn (2008), Improved estimates of upper-ocean warming and multi-decadal sea level rise, Nature, 453, 1090-1094, http:// dx.doi.org/10.1038/nature07080.

Dubois, C., et al. (2012), Future projections of the surface heat and water budgets of the Mediterranean sea in an ensemble of coupled atmosphereocean regional climate models, Climate Dyn., 39(7-8), pp. 1859-1884, doi:10.1007/s00382-011-1261-4.

Farmer, D., and L. Armi (1988), The flow of Atlantic water trough the Strait of Gibraltar, Progr. Oceanogr., 21, 1-105.

Fenoglio-Marc, L., J. Kusche, and M. Becker (2006), Mass variation in the Mediterranean Sea from GRACE and its validation by altimetry, steric and hydrologic fields, Geophys. Res. Lett., 33, L19606, doi:10.1029/ 2006 GL026851.

Fletchner, F. (2007), GRACE AOD1B Product Description Document GRACE 327-750. ftp://podaac.jpl.nasa.gov/allData/grace/ docs/AOD1B_20070413.pdf

Gomis, D., M. N. Tsimplis, M. Marcos, L. Fenoglio-Marc, B. Pérez, F. Raicich, I. Vilibić, G. Wöppelmann, and S. Monserrat (2012), Mediterranean sea level variability and trends, in Mediterranean climate: from past to future, edited by P. Lionello, pp. 251-293. Elsevier.

Greatbatch, R. J. (1994), A note on the representation of steric sea level in models that conserve volume rather than mass, J. Geophys. Res., 99(C6), 12767-12771.

Gualdi, S., et al. (2011), Future Climate Projections, in Regional Assessment of Climate Change in the Mediterranean, 2011, edited by A. Navarra, L. Tubiana, Springer, Dordrecht, The Netherlands. 


\section{JORDÀ AND GOMIS: STERIC AND MASS COMPONENTS OF SEA LEVEL VARIABILITY}

Huang, R. X., and X. Jin (2002), Sea surface elevation and bottom pressure anomalies due to thermohaline forcing. Part I: isolated perturbations, J. Phys. Ocean., 32, 2131-2150.

IPCC (2007), Climate Change 2008: The Physical Science Basis. Contribution of the Working Group I to the Fourth Assessment report of the Intergovernmental Panel on Climate Change, edited by S Solomon et al., Cambridge University Press, Cambridge, U. K. and New York, N. Y., USA.

Ishii, M., and M. Kimoto (2009), Reevaluation of historical ocean heat content variations with time-varying XBT and MBT depth bias corrections, J. Oceanogr., 65, 287-299, http://dx.doi.org/10.1007/s10872-009-0027-7.

Jordà, G., D. Gomis, and M. Marcos (2012a), Comment on "Storm surge frequency reduction in Venice under climate change", by Troccoli et al., Clim. Chang., 113(3-4), 1081-1087, doi:10.1007/s10584-011-0349-5.

Jordà, G., N. Marbà, and C. Duarte (2012b), Mediterranean seagrass vulnerable to regional climate warming, Nat. Clim. Change, doi:10.1038/ Nclimate1533.

Katsman, C. A., W. Hazeleger, S. S. Drijfhout, G. J. van Oldenborgh, and G. Burgers (2008), Climate scenarios of sea level rise for the northeast atlantic ocean: a study including the effects of ocean dynamics and gravity changes induced by ice melt, Clim. Chang., 91, 351-374, doi:10.1007/s10584-008-9442-9.

Kawabe, M. (1994), Mechanisms of Interannual Variations of Equatorial Sea Level Associated with El Niño, J. Phys. Oceanogr., 24, 979-993.

Leuliette, E. W., and L. Miller (2009), Closing the sea level rise budget with altimetry, Argo, and GRACE, Geophys. Res. Lett., 36, L04608, doi:10.1029/2008GL036010.

Levitus, S., et al. (2012), World ocean heat content and thermosteric sea level change (0-2000 m), 1955-2010, Geophys. Res. Lett., 39, L10603, doi:10.1029/2012GL051106.

Lorbacher K., S. J. Marsland, J. A. Church, S. M. Griffies, and D. Stammer (2012), Rapid barotropic sea level rise from ice sheet melting, J. Geophys. Res., 117, C06003, doi:10.1029/2011JC007733.

Lowe, J. A., and J. M. Gregory (2006), Understanding projections of sea level rise in a Hadley Centre coupled climate model, J. Geophys. Res., C11014. doi:10.1029/2005JC003421.

Marcos, M., and M. N. Tsimplis (2008), Comparison of results of AOGCMs in the Mediterranean Sea during the 21 st century, J. Geophys. Res., 113, C12028, doi:10.1111/j.1365-246X.2008.03892.x.

Mellor, G. L., and T. Ezer (1995), Sea level variations induced by heating and cooling: An evaluation of the Boussinesq approximation in ocean models, J. Geophys. Res., 100(C10), 20565-20577.

Miller, L., and B. C. Douglas (2004), Mass and volume contributions to twentieth-century global sea level rise, Nature, 428, 406-409, doi:10.1038/ nature 02309.
Mitrovica, J., M. E. Tamisiea, J. L. Davis, and G. A. Milne (2001), Recent mass balance of polar ice sheets inferred from patterns of global sea-level change, Nature, 409, 1026-1029.

Okumura, Y. M., C. Deser, A. Hu, A. Timmermann, and S.-P. Xie (2009), North Pacific Climate Response to Freshwater Forcing in the Subarctic North Atlantic: Oceanic and Atmospheric Pathways, J. Climate, 22, 1424-1445, doi:10.1175/ 2008JCLI2511.1.

Pardaens, A. K., J. M. Gregory, and J. A. Lowe (2011), A model study of factors influencing projected changes in regional sea level over the twenty-first century, Climate Dyn. 36, 2015-2033, doi:10.1007/s00382009-0738-X.

Pugh, D. T., and G. A. Maul (1999), Coastal sea level, prediction for climate change, Coastal and Estuarine Studies, 56, 377-404.

Somot, S., F. Sevault, and M. Déqué (2006), Transient climate change scenario simulation of the Mediterranean Sea for the 21 st century using a high-resolution ocean circulation model, Climate Dyn., 27(7-8), 851-879, doi:10.1007/s00382-006-0167-z.

Somot, S., F. Sevault, M. Déqué, and M. Crépon (2008), 21st century climate change scenario for the Mediterranean using a coupled atmosphere-ocean regional climate model, Global Planet. Change, 63, 112-126, doi:10.1016/j.gloplacha.2007.10.003.

Stammer, D. (2008), Response of the global ocean to Greenland and Antarctic ice melting, J. Geophys. Res., 113, C06022, doi:10.1029/ 2006JC004079.

Tsimplis, M. N., and M. Rixen (2002), Sea level in the Mediterranean Sea: The contribution of temperature and salinity changes, Geophys. Res. Lett., 29(23), 2136, doi:10.1029/ 2002GL015870.

Tsimplis, M. N., M. Marcos, and S. Somot (2008), 21st century Mediterranean sea level rise: Steric and atmospheric pressure contributions from a regional model, Global Planet. Change, 63, 105-111, doi:10.1016/ j.gloplacha.2007.09.006.

Tsimplis, M. N., G. Spada, M. Marcos, and N. Flemming (2011), Multidecadal sea level trends and land movements in the Mediterranean Sea with estimates of factors perturbing tide gauge data and cumulative uncertainties, Global Planet. Change, 76, 63-76, doi:10.1016/j. gloplacha.2010.12.002.

Vargas-Yáñez, M., P. Zunino, A. Benali, M. Delpy, F. Pastre, F. Moya, M. C. García-Martínez, and E. Tel (2010), How much is the western Mediterranean really warming and salting? J. Geophys. Res., 113, C04001, doi:10.1029/2009JC005816.

Willis, J. K., D. P. Chambers, and R. S. Nerem (2008), Assessing the globally averaged sea level budget on seasonal to interannual timescales, J. Geophys. Res., 113, C06015, doi:10.1029/2007JC004517.

Woodworth, P. L., and R. Player (2003), The Permanent Service for Mean Sea Level: an update to the 21st century, J. Coast. Res., 19, 287-295. 